\title{
The need for efforts to obtain high quality evidence in a one health approach.
}

\author{
Chang-Ro Lee ${ }^{1 \#}$, Jung Hun Lee ${ }^{1 \#}$, Kwang Seung Park${ }^{1}$, Jeong Ho Jeon ${ }^{1}$, Young Bae Kim², Byeong Chul \\ Jeong ${ }^{1}$, Sang Hee Lee ${ }^{{ }^{*}}$ \\ ${ }^{1}$ Department of Biological Sciences, National Leading Research Laboratory of Drug Resistance Proteomics, Myongji \\ University, 116 Myongjiro, Yongin, Gyeonggido, Republic of Korea \\ ${ }^{2}$ Biotechnology Program, North Shore Community College, 1 Ferncroft Road, Danvers, MA, USA \\ \#These authors contributed equally to this work
}

\begin{abstract}
The progressive increase of antibiotic resistance poses an alarming threat on public health worldwide. Although antibiotic resistance is a problem of human health, a one health approach to tackling antibiotic resistance is required, due to the effect of animal and environment on human health. To exactly estimate the impact of animal and environment on the spread of antibiotic resistance in human, scientific evidence with high quality is required. Molecular analysis of antibiotic-resistant bacteria through high-resolution, such as whole-genome sequencing, is suitable for obtaining credible evidence in examining the transmission of strains or genetic mobile elements responsible for antibiotic resistance among human, animal, and environment. In this paper, we discuss many observational studies using the whole-genome sequencing on various isolates collected from human, animal, and environment. These analyses suggest that more extensive surveillance based on whole-genome sequencing is required to accurately assess the potential threat of animal and environment on the spread of antibiotic resistance in human and that the effort to overcome various limitations in obtaining higher quality evidence is required.
\end{abstract}

Keywords: Antibiotic resistance, One health approach, Whole-genome sequencing, Animal, Environment.

Accepted on April 26, 2018

\section{Introduction}

From the first introduction in the market of a commercial antibiotic, antibiotics have been used in veterinary medicine as well as human medicine [1]. In addition to therapeutic purposes, antibiotics administered to food animals have been also used as growth-promoting agents to obtain sufficient amount of food [2]. Antibiotics for non-therapeutic purpose are generally supplied to food animals through feeding at very low concentrations for a long time $[3,4]$. Such antibiotic usage is known to be a dangerous practice, because antibiotics at low concentrations are able to generate selective pressure which could enrich antibiotic-resistant bacterial populations $[5,6]$. Therefore, antimicrobial growth promoters were banned in many European countries and the United States [4,7], but clinically important antibiotics are still being fed to food animals for growth promotion in some countries $[3,4]$. Several antibiotics have been used only in veterinary medicine, but some of them are structurally very similar to clinically important antimicrobial agents, such as fluoroquinolones and macrolides [8]. Most of commercial antibiotics have been used in both human and veterinary diseases for a long time [4].
These indiscriminate uses of antibiotics in livestock settings have caused the emergence of antimicrobial resistance.

Antimicrobial resistance has been considered a one health issue [9]. One health is an emerging concept that the human health is connected to the health of animal and environment. There is general scientific consensus that the use of antibiotics in veterinary medicine exerts selective pressure for the emergence of antimicrobial resistance in human [10]. Antimicrobialresistant bacteria selected by antibiotic use in veterinary medicine could spread to humans through foods, direct contact with animals, or environmental pathways $[10,11]$. However, to know why the recent antibiotic resistance crisis requires One Health approach, scientific evidence with high quality is required. Molecular analysis of antibiotic-resistant bacteria through high-resolution, such as whole-genome sequencing, has scientific merits in the elucidation of the connection between human health and animal (or environmental) health [12-14].

A recent study performed by Alicia et al. reported a retrospective, whole-genome sequencing study analyzing 288 Salmonella enterica serotype Typhimurium isolates obtained between 1911 and 1969 from 31 countries and from various 
sources, including human, animal, and food [15]. They showed the existence of ampicillin-resistant $S$. enterica serotype Typhimurium strains in human beings before ampicillin was released to the market. The authors suggested that the nonclinical use of narrow-spectrum penicillins, such as penicillin G, may exert selective pressure on the emergence of ampicillin-resistance $S$. enterica serotype Typhimurium in human. Based on this assumption, they highlighted the need for a One Health approach. To understand the connection between human health and animal (or environmental) health, we analysed all reported whole-genome sequencing studies examining the effect of animal and environment on antibiotic resistance of human. The analysis results suggest the following important aspects: (i) requirement for more extensive and observational evidences for the transmission of various strains or genetic mobile elements responsible for antibiotic resistance among human, animal, and environment; (ii) requirement for Randomized Controlled Trials (RCTs).

\section{Observational Evidences for the Transmission of Antibiotic Resistance among Human, Animal, and Environment}

There are many observational studies using the whole-genome sequencing tool to analyse the possibility of the transmission of genetic mobile elements or strains responsible for antibiotic resistance among human, animal, and environment (Table 1). The whole genome sequencing studies showed that the same antibiotic-resistant foodborne and zoonotic pathogens, such as S. enterica, Staphylococcus aureus, and Campylobacter sp., are detected in both human and animals [16-28]. For example, cefoxitin-resistant $S$. enterica serovar Heidelberg strains with 0 to 4 Single Nucleotide Variations (SNVs) (i.e. almost genetically identical strains) are identified in human, abattoir poultry, and retail poultry isolates [18]. This result suggests that the transmission of cefoxitin-resistant $S$. enterica serovar Heidelberg strains among human, abattoir poultry, and retail poultry sources may happen. The clonal transmission of opportunistic pathogens, such as Escherichia coli, Klebsiella pneumoniae, and Clostridium difficile, was also detected [29-38]. The whole genome sequencing of $C$. difficile strains, which are a commensal organism and a pathogen in both human and animal [39], showed that $C$. difficile isolates with identical (no SNP differences) and almost identical (less than two SNP differences) are detected in both farmers and pigs in the Netherlands [34]. Many $\beta$-lactam-resistant E. coli strains identified in human samples were also detected in animals [29,31,35-38] and environment [35,40,41]. These results indicate the complex transmission of $\beta$-lactam-resistant $E$. coli strains among human, animal, and environment.

In addition to the clonal transmission, the transmission of mobile genetic elements responsible for resistance of various antibiotics, such as $\beta$-lactam, colistin, and tetracycline, was also detected (Table 1). Colistin has been used in veterinary medicine for the prevention of infections and growth promotion for a long time, but it recently remains one of the last-resort drugs to treat infections caused by multidrug- resistant gram-negative pathogens, including Pseudomonas aeruginosa, Acinetobacter baumannii, E. coli, and $K$. pneumoniae [42]. Since a first report for the presence of the mcr-1 gene responsible for plasmid-mediated colistin resistance in commensal $E$. coli isolated in pig farms in China [43], the $m c r$ genes have been reported among various bacterial pathogens worldwide [42]. Many reports showed that the same plasmids containing the $\mathrm{mcr}$ genes are detected in E. coli isolates from human and animals [44-51]. For example, some colistin-resistant $E$. coli strains isolated from commercial chicken meat in Brazil carried an IncX4 plasmid containing the $m c r-1$ gene [47] and the sequence of this plasmid showed $100 \%$ identity to that of another IncX4 plasmid (pICBEC72Hmcr), which is detected in a colistin-resistant $E$. coli strain isolated from human in Brazil [52]. Notably, two IncX4 plasmids originating from environmental samples in Germany were almost identical to the pICBEC72Hmcr plasmid [53]. These results suggest that the mcr-1-containing IncX4 plasmids may be globally distributed in human, animal, and environment.

\section{Scope for Further Studies}

First, observational studies using whole-genome sequencing showed that the clonal transmission between human and animal is investigated in several antibiotic-resistant bacteria, including foodborne or zoonotic pathogens and commensal bacteria. However, these investigations are focused on several bacteria, such as $S$. aureus, E. coli, and $S$. enterica. It is required to examine whether the clonal transmission of other clinically important bacteria between human and animal is possible or not. To accurately assess public health impacts of antibiotic resistance in animal and environment, the continued monitoring based on whole-genome sequencing of bacterial isolates in human, animal, food and environmental sources is required. The study of Alicia et al. showed the existence of ampicillin-resistant $S$. enterica serotype Typhimurium strains in human beings before ampicillin were released to the market. The authors suggest that the non-clinical use of narrowspectrum penicillins, such as penicillin G, may exert selective pressure on the emergence of ampicillin-resistance $S$. enterica serotype Typhimurium in human. This result underlines the importance of One Health approaches and the merit of wholegenome sequencing. Therefore, the retrospective, wholegenome sequencing analysis of a large number of isolates collected from human, animal, or environment have to be continued.

Second, because observational studies provide low quality evidence, RCTs are needed for high quality evidence [54]. Many RCTs evaluating the effect of antimicrobial agents and probiotics on human health have provided high quality evidence on their effectiveness and safety [55-57]. However, there is no RCT to evaluate the transmission of antibioticresistant strains or genetic mobile elements between animal and human [58]. RCTs evaluating the transmission of antibiotic resistance from animal or environment to human are generally not feasible [59]. Nevertheless, the effort to overcome various 
limitations in obtaining high quality evidence is required, due to the overwhelming and urgent threat of antibiotic resistance on public health. In conclusion, these efforts will provide an important scientific basis for exactly estimating the impact of animal and environment on the spread of antibiotic resistance in human.

Table 1. Observational studies analyzing the possibility for the transmission of strains or genetic mobile elements responsible for antibiotic resistance among human, animal, and environment through whole genome sequencing.

\begin{tabular}{|c|c|c|c|c|}
\hline Source & The transmission of strains or genetic mobile elements & Antimicrobial agent & Species & References \\
\hline \multirow[t]{16}{*}{ Animal and human } & \multirow[t]{11}{*}{ Identification of the same antimicrobial-resistant strain } & \multirow[t]{6}{*}{$\beta$-Lactam } & Staphylococcus aureus & {$[17,19-22,24-26]$} \\
\hline & & & Salmonella enterica & {$[18,23,27]$} \\
\hline & & & Escherichia coli & {$[29,31,35-38]$} \\
\hline & & & Klebsiella pneumoniae & {$[30]$} \\
\hline & & & Campylobacter sp. & {$[28]$} \\
\hline & & & Enterobacteriaceae & {$[59]$} \\
\hline & & \multirow{2}{*}{$\begin{array}{l}\text { Quinolone } \\
\text { fluoroquinolone }\end{array}$} & Salmonella enterica & {$[16]$} \\
\hline & & & Escherichia coli & [32] \\
\hline & & Sulfamethoxazole & Salmonella enterica & {$[16]$} \\
\hline & & Tetracycline & Clostridium difficile & {$[34]$} \\
\hline & & Multidrug & Escherichia coli & [33] \\
\hline & \multirow{5}{*}{$\begin{array}{l}\text { Identification of the same genetic mobile element carrying the } \\
\text { antibiotic resistance gene }\end{array}$} & \multirow[t]{2}{*}{$\beta$-Lactam } & Escherichia coli & {$[29,31,36,60-62]$} \\
\hline & & & Salmonella enterica & {$[18,27,63]$} \\
\hline & & \multirow[t]{2}{*}{ Colistin } & Escherichia coli & [44-51] \\
\hline & & & Salmonella enterica & {$[64]$} \\
\hline & & Tetracycline & Staphylococcus aureus & {$[65]$} \\
\hline \multirow{5}{*}{$\begin{array}{l}\text { Environment } \\
\text { human }\end{array}$} & \multirow[t]{3}{*}{ Identification of the same antimicrobial-resistant strain } & \multirow[t]{2}{*}{$\beta$-Lactam } & Escherichia coli & {$[35,41,66]$} \\
\hline & & & Enterobacteriaceae & {$[59]$} \\
\hline & & Multidrug & Escherichia coli & {$[40]$} \\
\hline & \multirow{2}{*}{$\begin{array}{l}\text { Identification of the same genetic mobile element carrying the } \\
\text { antibiotic resistance gene }\end{array}$} & $\beta$-Lactam & Enterobacteriaceae & {$[67]$} \\
\hline & & Colistin & Escherichia coli & [53] \\
\hline
\end{tabular}

\section{Conflict of Interests}

The authors declare that they have no competing interests.

\section{Acknowledgments}

This work was supported by research grants from the Bio and Medical Technology Development Program of the NRF funded by the MSIT (numbers NRF-2017M3A9E4078014 and NRF-2017M3A9E4078017); the National Research Foundation of Korea (NRF) funded by the Ministry of Science and ICT (numbers NRF-2017R1A2B4002315 and NRF-2016R1C1B2010308); and the Research of Korea Centers for Disease Control and Prevention (number 2017NER5404-00).

\section{References}

1. McEwen SA. Antibiotic use in animal agriculture: what have we learned and where are we going? Anim Biotechnol 2006; 17: 239-250.

2. Woolhouse M, Ward M, van Bunnik B, Farrar J. Antimicrobial resistance in humans, livestock and the wider environment. Philos Trans R Soc Lond B Biol Sci 2015; 370: 20140083.

3. Cabello FC. Heavy use of prophylactic antibiotics in aquaculture: a growing problem for human and animal health and for the environment. Environ Microbiol 2006; 8: $1137-1144$.

4. Lee CR, Cho IH, Jeong BC, Lee SH. Strategies to minimize antibiotic resistance. Int J Environ Res Public Health 2013; 10: 4274-4305.

5. Gullberg E, Cao S, Berg OG, Ilback C, Sandegren L, Hughes D, Andersson DI. Selection of resistant bacteria at 
very low antibiotic concentrations. PLoS Pathog 2011; 7: 1002158 .

6. Alexander TW, Yanke JL, Reuter T, Topp E, Read RR, Selinger BL, McAllister TA. Longitudinal characterization of antimicrobial resistance genes in feces shed from cattle fed different subtherapeutic antibiotics. BMC Microbiol 2011; 11: 19.

7. Casewell M, Friis C, Marco E, McMullin P, Phillips I. The European ban on growth-promoting antibiotics and emerging consequences for human and animal health. J Antimicrob Chemother 2003; 52: 159-161.

8. Cantas L, Shah SQ, Cavaco LM, Manaia CM, Walsh F, Popowska M, Garelick H, Burgmann H, Sorum H. A brief multi-disciplinary review on antimicrobial resistance in medicine and its linkage to the global environmental microbiota. Front Microbiol 2013; 4: 96.

9. Robinson TP, Bu DP, Carrique-Mas J, Fevre EM, Gilbert M, Grace D, Hay SI, Jiwakanon J, Kakkar M, Kariuki S, Laxminarayan R, Lubroth J, Magnusson U, Thi Ngoc P, Van Boeckel TP, Woolhouse ME. Antibiotic resistance is the quintessential One Health issue. Trans R Soc Trop Med Hyg 2016; 110: 377-380.

10. da Costa PM, Loureiro L, Matos AJ. Transfer of multidrug-resistant bacteria between intermingled ecological niches: the interface between humans, animals and the environment. Int J Environ Res Public Health 2013; 10: 278-294.

11. Argudin MA, Deplano A, Meghraoui A, Dodemont M, Heinrichs A, Denis O, Nonhoff C, Roisin S. Bacteria from animals as a pool of antimicrobial resistance genes. Antibiotics (Basel) 2017; 6.

12. Koser CU, Ellington MJ, Peacock SJ. Whole-genome sequencing to control antimicrobial resistance. Trends Genet 2014; 30: 401-407.

13. Orlek A, Stoesser N, Anjum MF, Doumith M, Ellington MJ, Peto T, Crook D, Woodford N, Walker AS, Phan H, Sheppard AE. Plasmid classification in an era of wholegenome sequencing: application in studies of antibiotic resistance epidemiology. Front Microbiol 2017; 8: 182.

14. Schurch AC, van Schaik W. Challenges and opportunities for whole-genome sequencing-based surveillance of antibiotic resistance. Ann N Y Acad Sci 2017; 1388: 108-120.

15. Tran-Dien A, Le Hello S, Bouchier C, Weill FX. Early transmissible ampicillin resistance in zoonotic Salmonella enterica serotype Typhimurium in the late 1950s: a retrospective, whole-genome sequencing study. Lancet Infect Dis 2017; 18: 207-214.

16. Carroll LM, Wiedmann $\mathrm{M}$, den Bakker H, Siler J, Warchocki S, Kent D, Lyalina S, Davis M, Sischo W, Besser T, Warnick LD, Pereira RV. Whole-genome sequencing of drug-resistant Salmonella enterica isolates from dairy cattle and humans in New York and Washington states reveals source and geographic associations. Appl Environ Microbiol 2017; 83: 00140-00117.
17. Davis MF, Misic AM, Morris DO, Moss JT, Tolomeo P, Beiting DP, Nachamkin I, Lautenbach E, Rankin SC. Genome sequencing reveals strain dynamics of methicillin-resistant Staphylococcus aureus in the same household in the context of clinical disease in a person and a dog. Vet Microbiol 2015; 180: 304-307.

18. Edirmanasinghe R, Finley R, Parmley EJ, Avery BP, Carson C, Bekal S, Golding G, Mulvey MR. A wholegenome sequencing approach to study cefoxitin-resistant Salmonella enterica serovar Heidelberg isolates from various sources. Antimicrob Agents Chemother 2017; 61: 01919-01916.

19. Fox A, Pichon B, Wilkinson H, Doumith M, Hill RL, McLauchlin J, Kearns AM. Detection and molecular characterization of livestock-associated MRSA in raw meat on retail sale in North West England. Lett Appl Microbiol 2017; 64: 239-245.

20. Grontvedt CA, Elstrom P, Stegger M, Skov RL, Skytt Andersen P, Larssen KW, Urdahl AM, Angen O, Larsen J, Amdal S, Lotvedt SM, Sunde M, Bjornholt JV. Methicillin-resistant Staphylococcus aureus CC398 in humans and pigs in Norway: a One Health perspective on introduction and transmission. Clin Infect Dis 2016; 63: 1431-1438.

21. Harrison EM, Coll F, Toleman MS, Blane B, Brown NM, Torok ME, Parkhill J, Peacock SJ. Genomic surveillance reveals low prevalence of livestock-associated methicillin-resistant Staphylococcus aureus in the East of England. Sci Rep 2017; 7: 7406.

22. Harrison EM, Paterson GK, Holden MT, Larsen J, Stegger M, Larsen AR, Petersen A, Skov RL, Christensen JM, Bak Zeuthen A, Heltberg O, Harris SR, Zadoks RN, Parkhill J, Peacock SJ, Holmes MA. Whole genome sequencing identifies zoonotic transmission of MRSA isolates with the novel mecA homologue mecC. EMBO Mol Med 2013; 5: 509-515.

23. Hindermann D, Gopinath G, Chase H, Negrete F, Althaus D, Zurfluh K, Tall BD, Stephan R, Nuesch-Inderbinen M. Salmonella enterica serovar Infantis from food and human infections, Switzerland, 2010-2015: poultry-related multidrug resistant clones and an emerging ESBL producing clonal lineage. Front Microbiol 2017; 8: 1322.

24. Islam MZ, Espinosa-Gongora C, Damborg P, Sieber RN, Munk R, Husted L, Moodley A, Skov R, Larsen J, Guardabassi L. Horses in Denmark are a reservoir of diverse clones of methicillin-resistant and -susceptible Staphylococcus aureus. Front Microbiol 2017; 8: 543.

25. Sahibzada S, Abraham S, Coombs GW, Pang S, Hernandez-Jover M, Jordan D, Heller J. Transmission of highly virulent community-associated MRSA ST93 and livestock-associated MRSA ST398 between humans and pigs in Australia. Sci Rep 2017; 7: 5273.

26. Spoor LE, McAdam PR, Weinert LA, Rambaut A, Hasman H, Aarestrup FM, Kearns AM, Larsen AR, Skov RL, Fitzgerald JR. Livestock origin for a human pandemic clone of community-associated methicillin-resistant Staphylococcus aureus. MBio 2013; 4: 00356-00313. 
27. Tate H, Folster JP, Hsu CH, Chen J, Hoffmann M, Li C, Morales C, Tyson GH, Mukherjee S, Brown AC, Green A, Wilson W, Dessai U, Abbott J, Joseph L, Haro J, Ayers S, McDermott PF, Zhao S. Comparative analysis of extended-spectrum- $\beta$-lactamase CTX-M-65-producing Salmonella enterica serovar Infantis isolates from humans, food animals, and retail chickens in the United States. Antimicrob Agents Chemother 2017; 61: 00488-00417.

28. Weis AM, Storey DB, Taff CC, Townsend AK, Huang BC, Kong NT, Clothier KA, Spinner A, Byrne BA, Weimer BC. Genomic comparison of Campylobacter spp. and their potential for zoonotic transmission between birds, primates, and livestock. Appl Environ Microbiol 2016; 82: 7165-7175.

29. Berg ES, Wester AL, Ahrenfeldt J, Mo SS, Slettemeas JS, Steinbakk M, Samuelsen O, Grude N, Simonsen GS, Lohr IH, Jorgensen SB, Tofteland S, Lund O, Dahle UR, Sunde M. Norwegian patients and retail chicken meat share cephalosporin-resistant Escherichia coli and IncK/ blaCMY-2 resistance plasmids. Clin Microbiol Infect 2017; 23: 407-415.

30. Davis GS, Waits K, Nordstrom L, Weaver B, Aziz M, Gauld L, Grande H, Bigler R, Horwinski J, Porter S, Stegger M, Johnson JR, Liu CM, Price LB. Intermingled Klebsiella pneumoniae populations between retail meats and human urinary tract infections. Clin Infect Dis 2015; 61: 892-899.

31. de Been M, Lanza VF, de Toro M, Scharringa J, Dohmen W, Du Y, Hu J, Lei Y, Li N, Tooming-Klunderud A, Heederik DJ, Fluit AC, Bonten MJ, Willems RJ, de la Cruz F, van Schaik W. Dissemination of cephalosporin resistance genes between Escherichia coli strains from farm animals and humans by specific plasmid lineages. PLoS Genet 2014; 10: 1004776.

32. Falgenhauer L, Imirzalioglu $\mathrm{C}$, Ghosh $\mathrm{H}$, Gwozdzinski K, Schmiedel J, Gentil K, Bauerfeind R, Kampfer P, Seifert H, Michael GB, Schwarz S, Pfeifer Y, Werner G, Pietsch M, Roesler U, Guerra B, Fischer J, Sharp H, Kasbohrer A, Goesmann A, Hille K, Kreienbrock L, Chakraborty T. Circulation of clonal populations of fluoroquinoloneresistant CTX-M-15-producing Escherichia coli ST410 in humans and animals in Germany. Int J Antimicrob Agents 2016; 47: 457-465.

33. Hussain A, Shaik S, Ranjan A, Nandanwar N, Tiwari SK, Majid M, Baddam R, Qureshi IA, Semmler T, Wieler LH, Islam MA, Chakravortty D, Ahmed N. Risk of transmission of antimicrobial resistant Escherichia coli from commercial broiler and free-range retail chicken in India. Front Microbiol 2017; 8: 2120.

34. Knetsch CW, Connor TR, Mutreja A, van Dorp SM, Sanders IM, Browne HP, Harris D, Lipman L, Keessen EC, Corver J, Kuijper EJ, Lawley TD. Whole genome sequencing reveals potential spread of Clostridium difficile between humans and farm animals in the Netherlands, 2002 to 2011. Euro Surveill 2014; 19: 20954.
35. Moremi N, Manda EV, Falgenhauer L, Ghosh $\mathrm{H}$, Imirzalioglu C, Matee M, Chakraborty $\mathrm{T}$, Mshana SE. Predominance of CTX-M-15 among ESBL producers from environment and fish gut from the shores of lake Victoria in Mwanza, Tanzania. Front Microbiol 2016; 7: 1862.

36. Seni J, Falgenhauer L, Simeo N, Mirambo MM, Imirzalioglu C, Matee M, Rweyemamu M, Chakraborty T, Mshana SE. Multiple ESBL-producing Escherichia coli sequence types carrying quinolone and aminoglycoside resistance genes circulating in companion and domestic farm animals in Mwanza, Tanzania, harbor commonly occurring plasmids. Front Microbiol 2016; 7: 142.

37. Wang Y, Zhang R, Li J, Wu Z, Yin W, Schwarz S, Tyrrell JM, Zheng Y, Wang S, Shen Z, Liu Z, Liu J, Lei L, Li M, Zhang Q, Wu C, Zhang Q, Wu Y, Walsh TR, Shen J. Comprehensive resistome analysis reveals the prevalence of NDM and MCR-1 in Chinese poultry production. Nat Microbiol 2017; 2: 16260.

38. Zhang PLC, Shen X, Chalmers G, Reid-Smith RJ, Slavic D, Dick H, Boerlin P. Prevalence and mechanisms of extended-spectrum cephalosporin resistance in clinical and fecal Enterobacteriaceae isolates from dogs in Ontario, Canada. Vet Microbiol 2018; 213: 82-88.

39. Gould LH, Limbago B. Clostridium difficile in food and domestic animals: a new foodborne pathogen? Clin Infect Dis 2010; 51: 577-582.

40. Gomi R, Matsuda T, Matsumura Y, Yamamoto M, Tanaka M, Ichiyama S, Yoneda M. Whole-genome analysis of antimicrobial-resistant and extraintestinal pathogenic Escherichia coli in river water. Appl Environ Microbiol 2017; 83: 02703-02716.

41. Jorgensen SB, Soraas AV, Arnesen LS, Leegaard TM, Sundsfjord A, Jenum PA. A comparison of extended spectrum $\beta$-lactamase producing Escherichia coli from clinical, recreational water and wastewater samples associated in time and location. PLoS One 2017; 12: 0186576.

42. Sun J, Zhang H, Liu YH, Feng Y. Towards understanding MCR-like colistin resistance. Trends Microbiol 2018.

43. Liu YY, Wang Y, Walsh TR, Yi LX, Zhang R, Spencer J, Doi Y, Tian G, Dong B, Huang X, Yu LF, Gu D, Ren H, Chen X, Lv L, He D, Zhou H, Liang Z, Liu JH, Shen J. Emergence of plasmid-mediated colistin resistance mechanism MCR-1 in animals and human beings in China: a microbiological and molecular biological study. Lancet Infect Dis 2016; 16: 161-168.

44. Brauer A, Telling K, Laht M, Kalmus P, Lutsar I, Remm $\mathrm{M}$, Kisand V, Tenson T. Plasmid with colistin resistance gene mcr- 1 in extended-spectrum- $\beta$-lactamase-producing Escherichia coli strains isolated from pig slurry in Estonia. Antimicrob Agents Chemother 2016; 60: 6933-6936.

45. Chiou CS, Chen YT, Wang YW, Liu YY, Kuo HC, Tu YH, Lin AC, Liao YS, Hong YP. Dissemination of mcr-1carrying plasmids among colistin-resistant Salmonella 
strains from humans and food-producing animals in Taiwan. Antimicrob Agents Chemother 2017; 61: 00338-00317.

46. Duggett NA, Sayers E, Abuoun M, Ellis RJ, NunezGarcia J, Randall L, Horton R, Rogers J, Martelli F, Smith RP, Brena C, Williamson S, Kirchner M, Davies R, Crook D, Evans S, Teale C, Anjum MF. Occurrence and characterization of mcr-1-harbouring Escherichia coli isolated from pigs in Great Britain from 2013 to 2015. J Antimicrob Chemother 2017; 72: 691-695.

47. Monte DF, Mem A, Fernandes MR, Cerdeira L, Esposito F, Galvao JA, Franco B, Lincopan N, Landgraf M. Chicken meat as a reservoir of colistin-resistant Escherichia coli strains carrying mor-1 genes in South America. Antimicrob Agents Chemother 2017; 61: 02718-02716.

48. Pulss S, Semmler T, Prenger-Berninghoff E, Bauerfeind R, Ewers C. First report of an Escherichia coli strain from swine carrying an OXA-181 carbapenemase and the colistin resistance determinant MCR-1. Int J Antimicrob Agents 2017; 50: 232-236.

49. Roschanski N, Falgenhauer L, Grobbel M, Guenther S, Kreienbrock L, Imirzalioglu C, Roesler U. Retrospective survey of mcr-1 and mcr-2 in German pig-fattening farms, 2011-2012. Int J Antimicrob Agents 2017; 50: 266-271.

50. Yin W, Li H, Shen Y, Liu Z, Wang S, Shen Z, Zhang R, Walsh TR, Shen J, Wang Y. Novel plasmid-mediated colistin resistance gene mcr-3 in Escherichia coli. MBio 2017; 8: e00543-00517.

51. Zurfluh K, Nuesch-Inderbinen M, Klumpp J, Poirel L, Nordmann P, Stephan R. Key features of mcr-1-bearing plasmids from Escherichia coli isolated from humans and food. Antimicrob Resist Infect Control 2017; 6: 91.

52. Fernandes MR, McCulloch JA, Vianello MA, Moura Q, Perez-Chaparro PJ, Esposito F, Sartori L, Dropa M, Matte MH, Lira DP, Mamizuka EM, Lincopan N. First Report of the Globally Disseminated IncX4 Plasmid Carrying the mcr-1 Gene in a Colistin-Resistant Escherichia coli Sequence Type 101 Isolate from a Human Infection in Brazil. Antimicrob Agents Chemother 2016; 60: 6415-6417.

53. Guenther S, Falgenhauer L, Semmler T, Imirzalioglu C, Chakraborty T, Roesler U, Roschanski N. Environmental emission of multiresistant Escherichia coli carrying the colistin resistance gene mcr-1 from German swine farms. J Antimicrob Chemother 2017; 72: 1289-1292.

54. Atkins D, Best D, Briss PA, Eccles M, Falck-Ytter Y, Flottorp S, Guyatt GH, Harbour RT, Haugh MC, Henry D, Hill S, Jaeschke R, Leng G, Liberati A, Magrini N, Mason J, Middleton P, Mrukowicz J, OConnell D, Oxman AD, Phillips B, Schunemann HJ, Edejer T, Varonen H, Vist GE, Williams JW, Jr., Zaza S, Group GW. Grading quality of evidence and strength of recommendations. BMJ 2004; 328: 1490 .

55. Goldenberg JZ, Yap C, Lytvyn L, Lo CK, Beardsley J, Mertz D, Johnston BC. Probiotics for the prevention of
Clostridium difficile-associated diarrhea in adults and children. Cochrane Database Syst Rev 2017; 12: 006095.

56. Toh SL, Boswell-Ruys CL, Lee BSB, Simpson JM, Clezy KR. Probiotics for preventing urinary tract infection in people with neuropathic bladder. Cochrane Database Syst Rev 2017; 9: CD010723.

57. McCallum GB, Plumb EJ, Morris PS, Chang AB. Antibiotics for persistent cough or wheeze following acute bronchiolitis in children. Cochrane Database Syst Rev 2017; 8: CD009834.

58. Hoelzer K, Wong N, Thomas J, Talkington K, Jungman E, Coukell A. Antimicrobial drug use in food-producing animals and associated human health risks: what, and how strong, is the evidence? BMC Vet Res 2017; 13: 211.

59. Daehre K, Projahn M, Semmler T, Roesler U, Friese A. Extended-spectrum $\beta$-lactamase-/AmpC $\quad \beta$-lactamaseproducing Enterobacteriaceae in broiler farms: transmission dynamics at farm level. Microb Drug Resist 2017.

60. Hansen KH, Bortolaia V, Nielsen CA, Nielsen JB, Schonning K, Agerso Y, Guardabassi L. Host-specific patterns of genetic diversity among IncI1-I $\gamma$ and IncK plasmids encoding CMY-2 $\beta$-lactamase in Escherichia coli isolates from humans, poultry meat, poultry, and dogs in Denmark. Appl Environ Microbiol 2016; 82: 4705-4714.

61. Norizuki C, Wachino JI, Suzuki M, Kawamura K, Nagano N, Kimura K, Arakawa Y. Specific blaCTX-M-8/IncI1 plasmid transfer among genetically diverse Escherichia coli isolates between humans and chickens. Antimicrob Agents Chemother 2017; 61: e00663-00617.

62. Seiffert SN, Carattoli A, Schwendener S, Collaud A, Endimiani A, Perreten V. Plasmids carrying blaCMY -2/4 in Escherichia coli from poultry, poultry meat, and humans belong to a novel IncK subgroup designated IncK2. Front Microbiol 2017; 8: 407.

63. Franco A, Leekitcharoenphon P, Feltrin F, Alba P, Cordaro G, Iurescia M, Tolli R, DIncau M, Staffolani M, Di Giannatale E, Hendriksen RS, Battisti A. Emergence of a clonal lineage of multidrug-resistant ESBL-producing Salmonella infantis transmitted from broilers and broiler meat to humans in Italy between 2011 and 2014. PLoS One 2015; 10: 0144802.

64. Anjum MF, Duggett NA, AbuOun M, Randall L, NunezGarcia J, Ellis RJ, Rogers J, Horton R, Brena C, Williamson S, Martelli F, Davies R, Teale C. Colistin resistance in Salmonella and Escherichia coli isolates from a pig farm in Great Britain. J Antimicrob Chemother 2016; 71: 2306-2313.

65. de Vries LE, Hasman H, Jurado Rabadan S, Agerso Y. Sequence-based characterization of Tn5801-like genomic islands in tetracycline-resistant Staphylococcus pseudintermedius and other Gram-positive bacteria from humans and animals. Front Microbiol 2016; 7: 576.

66. Gomi R, Matsuda T, Matsumura Y, Yamamoto M, Tanaka M, Ichiyama S, Yoneda M. Occurrence of clinically important Lineages, including the sequence type $131 \mathrm{C} 1$ - 
The need for efforts to obtain high quality evidence in a one health approach

M27 subclone, among extended-spectrum- $\beta$-lactamaseproducing Escherichia coli in wastewater. Antimicrob Agents Chemother 2017; 61: 00564-00517.

67. Yao Y, Lazaro-Perona F, Falgenhauer L, Valverde A, Imirzalioglu C, Dominguez L, Canton R, Mingorance J, Chakraborty T. Insights into a novel blaKPC-2-encoding IncP-6 plasmid reveal carbapenem-resistance circulation in several Enterobacteriaceae species from wastewater and a hospital source in Spain. Front Microbiol 2017; 8: 1143 .

\section{"Correspondence to}

Sang Hee Lee

Department of Biological Sciences

National Leading Research Laboratory of Drug Resistance Proteomics

Republic of Korea 